\title{
Radiological Assessment of Femoroacetabular Impingement Morphology Using Computed Tomography in an Asymptomatic Young Population
}

\author{
Memik Teke, ${ }^{1,}$ Cemil Goya, ${ }^{1}$ Celil Alemdar, ${ }^{2}$ Cihad Hamidi, ${ }^{1}$ Mehmet Guli Cetincakmak,,${ }^{1}$ Salih \\ Hattapoglu, ${ }^{1}$ Emin Ozkul, ${ }^{2}$ and Aslan Bilici ${ }^{1}$ \\ ${ }^{1}$ Department of Radiology, Medical School, Dicle University, Diyarbakir, Turkey \\ ${ }^{2}$ Department of Orthopaedics, Medical School, Dicle University, Diyarbakir, Turkey \\ "Corresponding author: Memik Teke, Department of Radiology, Medical School, Dicle University, Diyarbakir, Turkey. Tel: +90-4122484810, Fax: +90-4122488115, E-mail: \\ memikteke@gmail.com
}

Received 2014 July 07; Revised 2014 November 27; Accepted 2015 February 16.

\begin{abstract}
Background: Femoroacetabular impingement (FAI) is one cause of hip pain, and is an under-recognized cause of early osteoarthritis, especially in young and active people. The prevalence of FAI in adults is approximately $10-15 \%$ and depending on the clinical and radiographic findings, two types of impingement (which are often present in combination) can be distinguished: the cam type and the pincer type. Most patients (86\%) have a combination of both forms of impingement.

Objectives: The aim of our study was to evaluate the prevalence and gender differences in the radiological parameters associated with cam and pincer FAI morphologies in an asymptomatic young population, using computed tomography (CT).

Patients and Methods: A retrospective study was performed on 200 individuals (400 hip joints), ranging from 15 - 40 years of age, who were seen in our hospital between July of 2013 and April of 2014 for nonspecific abdominal pain. Multiplanar reformatted CT images of these patients were assessed for the existence of radiological abnormalities, and six measurements (acetabular version angle, acetabular index, lateral center-edge angle, alpha angle in the oblique axial plane, alpha angle in the radial [one o'clock position] plane, and femoral head neck offset) were made relating to the FAI.

Results: The data showed that $69.2 \%$ of the women's joints and $60.5 \%$ of the men's joints had at least one abnormal parameter associated with the FAI. Of the joints, $34.25 \%$ had two or more abnormal parameters, and in 38 (19\%) of the patients, these abnormalities were bilateral. Unlike previous studies, we found that only $15 \%$ of the joints had mixed FAI morphologies.

Conclusion: The prevalence of radiological parameters associated with FAI is high, even in an asymptomatic young population. This high frequency of features may suggest that the threshold values have been set too low in the current literature, or that these findings may reflect anatomical variation rather than true pathological abnormalities.
\end{abstract}

Keywords: Femoroacetabular Impingement, Acetabular Version, Femoral Head, Alpha Angle

\section{Background}

Femoroacetabular impingement (FAI) is one cause of hip pain, and is an under-recognized cause of early osteoarthritis, especially in young and active people $(1,2)$. The prevalence of FAI in adults is approximately 10-15\% (3) and, depending on the clinical and radiographic findings, two types of impingement (which are often present in combination) can be distinguished: the cam type and the pincer type. Most patients (86\%) have a combination of both forms of impingement (4). The main abnormality in the cam type of impingement is a reduced offset between the femoral head and neck, caused by an aspherical portion of the femoral head-neck junction. In pincer impingement, the acetabular socket may be too deep (coxa profunda) or retroverted, or the acetabular rim may curve downward.
These variances predispose repetitive contact between the femoral head, acetabular articular surface, and labral surface, causing labral degeneration and irreversible chondral damage during sports and daily activities. If the underlying cause of femoroacetabular impingement is not addressed, it can progress, and result in degenerative diseases of the hip joint $(4,5)$.

The diagnosis of FAI is based on a suggestive pattern of pain, restricted motion, clinical examination, and imaging study evidence of the morphological abnormalities associated with FAI. Imaging findings, including an increased alpha angle (AA), decreased femoral head-neck offset (FHNO), abnormal center-edge angle (CEA), acetabular retroversion, coxa profunda, and protrusio acetabuli, support the diagnosis of FAI. Early diagnosis and appropriate treatment alter the course of degenerative joint disease, re- 
ducing the symptoms and preventing the development of end stage osteoarthritis (6). Moreover, early diagnosis alters the surgical approach, which is less invasive than in cases of dysplasia.

\section{Objectives}

The goal of our study was to determine the prevalence and gender differences in the radiological parameters associated with FAIs in an asymptomatic population, in order to evaluate the threshold values of normal and abnormal group. FAI is becoming increasingly accepted as a factor in damage of the hip; therefore, defined standards of assessment and treatment need to be established to provide high sensitivity and specificity in its diagnosis.

\section{Patients and Methods}

This study was approved by the institutional review board and protocol review committee. For this research, we retrospectively reviewed the CT images of 200 patients, ranging from 15 - 40 years old, who had been seen at our hospital between July of 2013 and April of 2014 for nonspecific abdominal pain. All of the abdominal scans were obtained using a 64-detector Brilliance CT scanner (Philips Medical Systems, Cleveland, Ohio), and included the hip joints in the imaged range. The radiology department and hospital database were reviewed with regard to the history of hip disease or the hip symptoms of the patients.

The exclusion criteria for this study included the presence of morphological and/or anatomical abnormalities compatible with childhood diseases, interventions, trauma sequelae, or tumoral disease. In addition, those patients with a previous history of hip disease, hip imaging, and pelvic imaging were excluded, and those images showing inadequate technical quality were excluded. The raw CT data were loaded into a workstation (Extended Brilliance Workspace, version 3.5.0.2254, Philips Medical Systems, Cleveland), and multiplanar reformatted images were generated using the bone and soft tissue algorithm. The reformatted CT images were corrected to prevent measurement errors generated by the patient's position, using the workstation's oblique tool. Four hundred hip joints (200 patients) were analyzed for the radiological parameters of FAI, with the following measurements conducted on each hip joint:

1. We measured the acetabular version (AV) angle between a line joining the anterior and posterior rims of the acetabulum, and a line perpendicular to a tangent running through both posterior corners of the acetabula, on the axial reformatted image (Figure 1B). The measurement level was determined by cross-referencing the images obtained in the coronal plane, where the acetabular cup is the deepest (Figure 1A). An angle of less than $15^{\circ}(7)$ was defined as acetabular retroversion.

2. We assessed the acetabular index (AI) (Figure 2) and lateral center-edge angle (LCEA) (Figure 3) using the transparent 3-dimensional pelvis model. An AI of less than $0^{\circ}$ (1) and LCEA of greater than $40^{\circ}$ (8) were defined as overcoverage of the femoral head by the acetabulum (coxa profunda), consistent with pincer type morphological characteristics.

3. We measured the AA in the oblique axial plane (Figure 4) and the radial (one o'clock position) plane (Figure 5) on the reformatted images. The line joining the center of the femoral head and the center of the femoral neck was determined as the rotational axis (femoral neck axis). The one o'clock position alpha angles were measured in the anterosuperior quadrant of the femoral head and neck on the radial reformatted images. An angle greater than $55^{\circ}(9)$ was defined as a cam type morphological abnormality.

4. We measured the distance between two lines, one parallel to the anterior aspect of the femoral neck cortex, and the other one parallel to the anterior cortex of the femoral head, as the FHNO in the oblique axial plane (Figure 6). A decreased FHNO was defined as $<8 \mathrm{~mm}$ (8).

All of the oblique axial plane and radial plane AAs were measured by two experienced musculoskeletal radiologists. The other measurements, including the AV, AI, FHNO, and LCEA, were measured by one radiologist. Twenty randomly selected patients were re-evaluated by the same radiologists to assess the intra- and interobserver variability of the AA measurements.

SPSS software for Windows ver. 16 (SPSS Inc., Chicago, Il) was used for the statistical data analysis. The variables were investigated using the Kolmogorov-Smirnov test to determine whether or not they were normally distributed. Since the parameters were normally distributed, the correlation coefficients and their significance were calculated using the Pearson's test. Additionally, the Bland-Altman plot method was used for the comparisons of the intra-and interobserver variability of the AAs. An independent sample $t$ test was used to assess the gender differences in the $\mathrm{AV}$, AI, LCEA, and FHNO.

\section{Results}

Four hundred hip joints from 200 patients (91 females, 109 males), ranging from 15 - 40 years old (mean age: 27.9 \pm 7.5 ), were assessed for the parameters associated with FAI. One hundred and fifteen joints $(28.75 \%)$ had only pincer FAIs, 83 joints (20.75\%) had only cam FAIs, and 60 joints (15\%) had mixed FAIs with at least one abnormal parameter. 

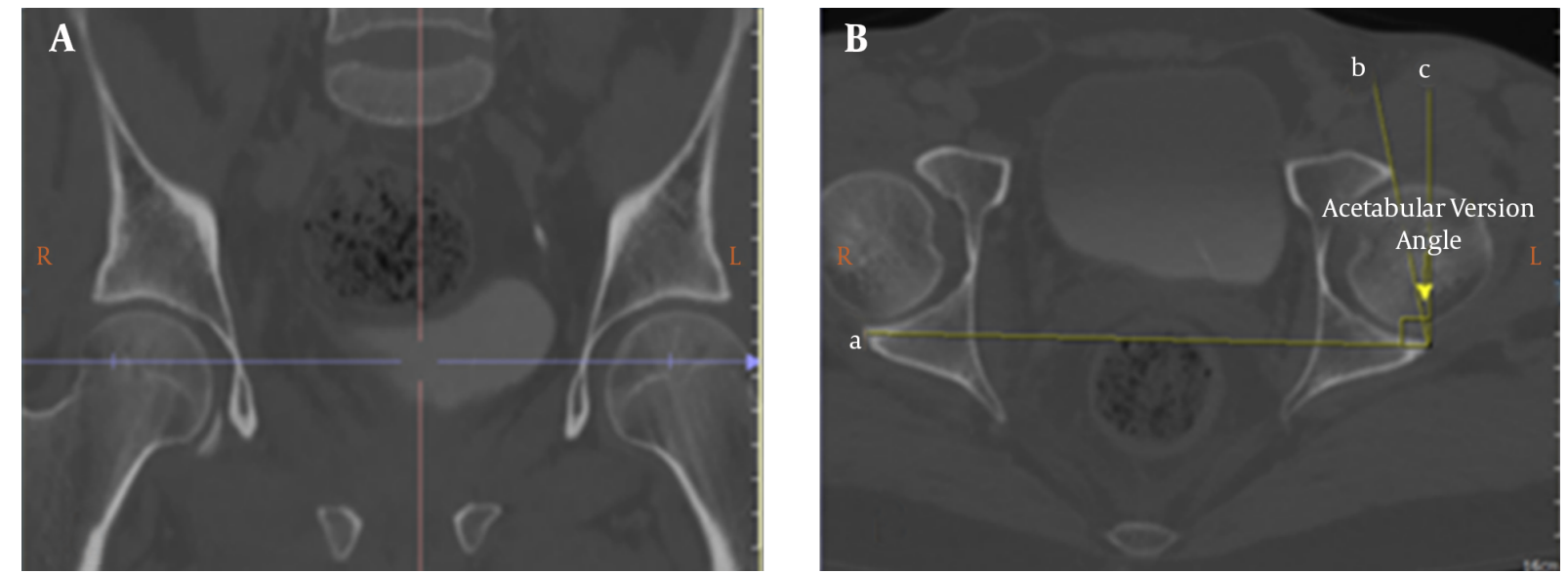

Figure 1. Acetabular version angle. A, Reference plane for acetabular version angle measurement; B, Line a was drawn between the posterior corners of the acetabula. Line b is tangential to the anterior and posterior rims of the acetabulum. Line $\mathrm{c}$ is perpendicular to line $\mathrm{a}$.

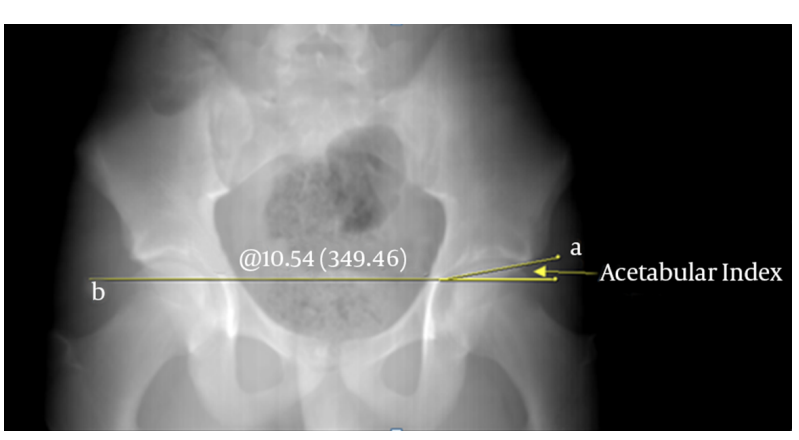

Figure 2. Acetabular index. Line a joins the lateral edge of the acetabulum and the medial end of the sclerotic weight bearing surface of the acetabulum; line $b$ has been drawn between the two ends of the sclerotic arched weight bearing area of the acetabular roof.

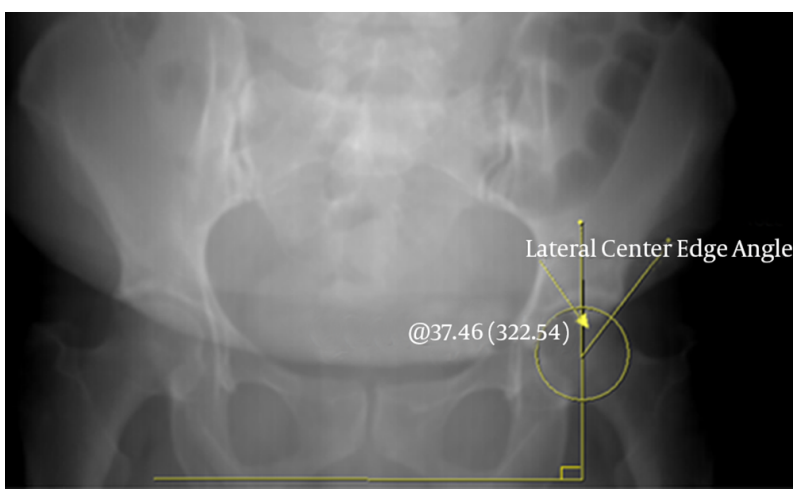

Figure 3. Lateral center edge angle. Line joins the lateral edge of the acetabulum and the center of the femoral head. The vertical line is perpendicular to the horizontal line joining the ischial tuberosities.
In all, $64.5 \%$ of the 400 joints had at least one abnormal parameter. One hundred and twenty-six of 182 joints (69.2\%) in the women and 132 of 218 joints (60.5\%) in the men had at least one abnormal parameter. Moreover, $34.25 \%$ of the joints had two or more abnormal parameters, and these abnormalities were bilateral in 38 patients (19\%). Sixtyseven of 218 joints (30.7\%) in the men and 70 of 182 joints (38.5\%) in the women had two or more abnormalities associated with FAIs. Mixed morphological features (cam and pincer types) were found in $15 \%$ of the joints: 36 of 182 joints $(19.8 \%)$ in the women and 24 of 218 joints (11\%) in the men.

With regard to the cam FAI morphology, there were 243 cam type abnormalities in the sample population. In the male patients, 77 of 218 joints (35.3\%) had at least one, and 48 of 218 joints (22\%) had two or more abnormalities associated with cam FAIs. However, in the female patients, 66 of 182 joints (36.3\%) had at least one, and 39 of 182 joints (21.4\%) had two or more abnormalities associated with cam FAIs. Table 1 shows the number and distribution of the cam type abnormalities according to side and sex.

The AAs of the femoral head-neck junction ranged from $33.6^{\circ}$ to $65.6^{\circ}$ (mean: $47.3^{\circ}$, SD: $7.7^{\circ}$, median: $45.4^{\circ}$ ) in the oblique axial plane, and from $36.8^{\circ}$ to $67.4^{\circ}$ (mean: $51.6^{\circ}$, SD: $7.9^{\circ}$, median: $49.8^{\circ}$ ) in the radial plane (one o'clock position). The AA was found to be greater than $55^{\circ}$ in 84 joints in the oblique axial plane, and 119 joints in the radial plane. There was a statistically significant difference between the $A A$ values of the oblique axial plane and the radial plane $(P$ $<0.001$ ), and the AA values of the radial plane were higher than those of the oblique axial plane. Therefore, no statistically significant gender difference was detected for the oblique axial plane AA or the radial plane AA $(\mathrm{P}>0.05)$.

There was a good correlation between the two radiolo- 

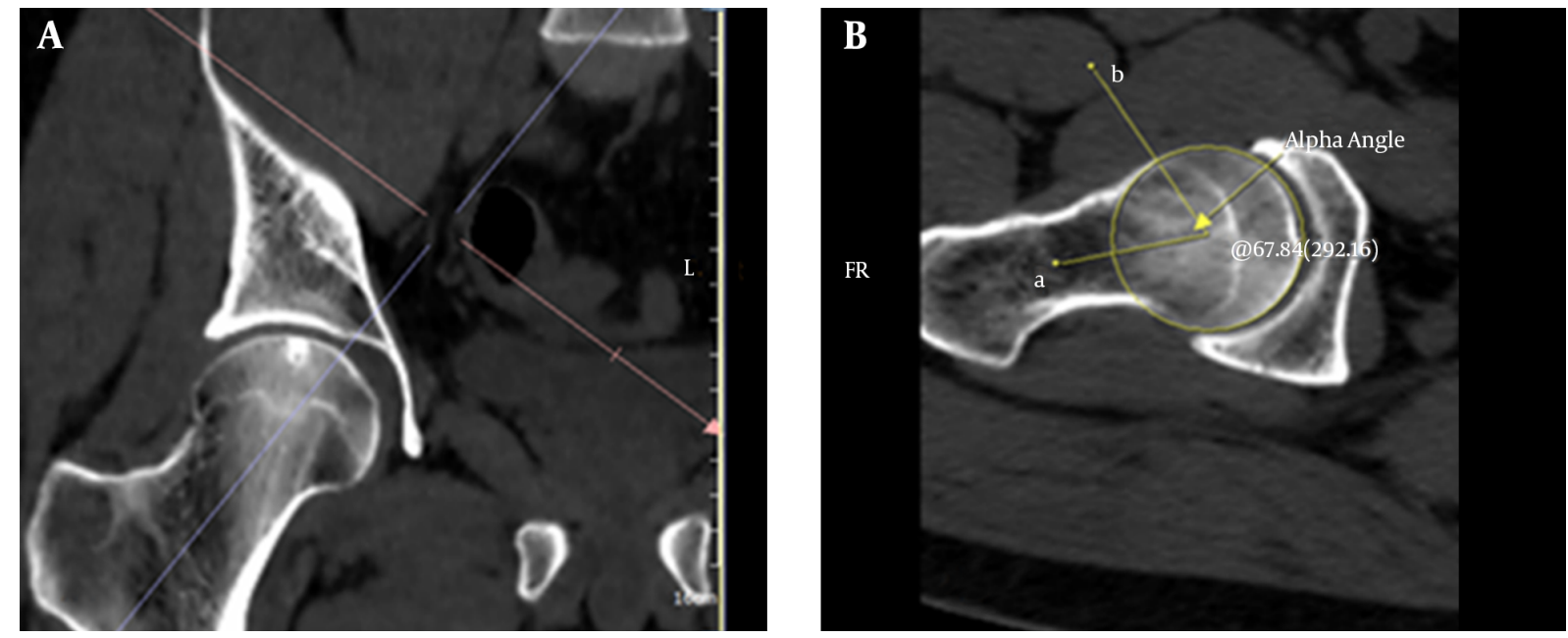

Figure 4. Alpha angle measurement. A, Reference plane for measuring the alpha angle; B, The angle was measured between line a, crossing the central axis of the femoral neck, and line $b$, joining the center of the femoral head and the point where the radius of the femoral head exceeds the circle.
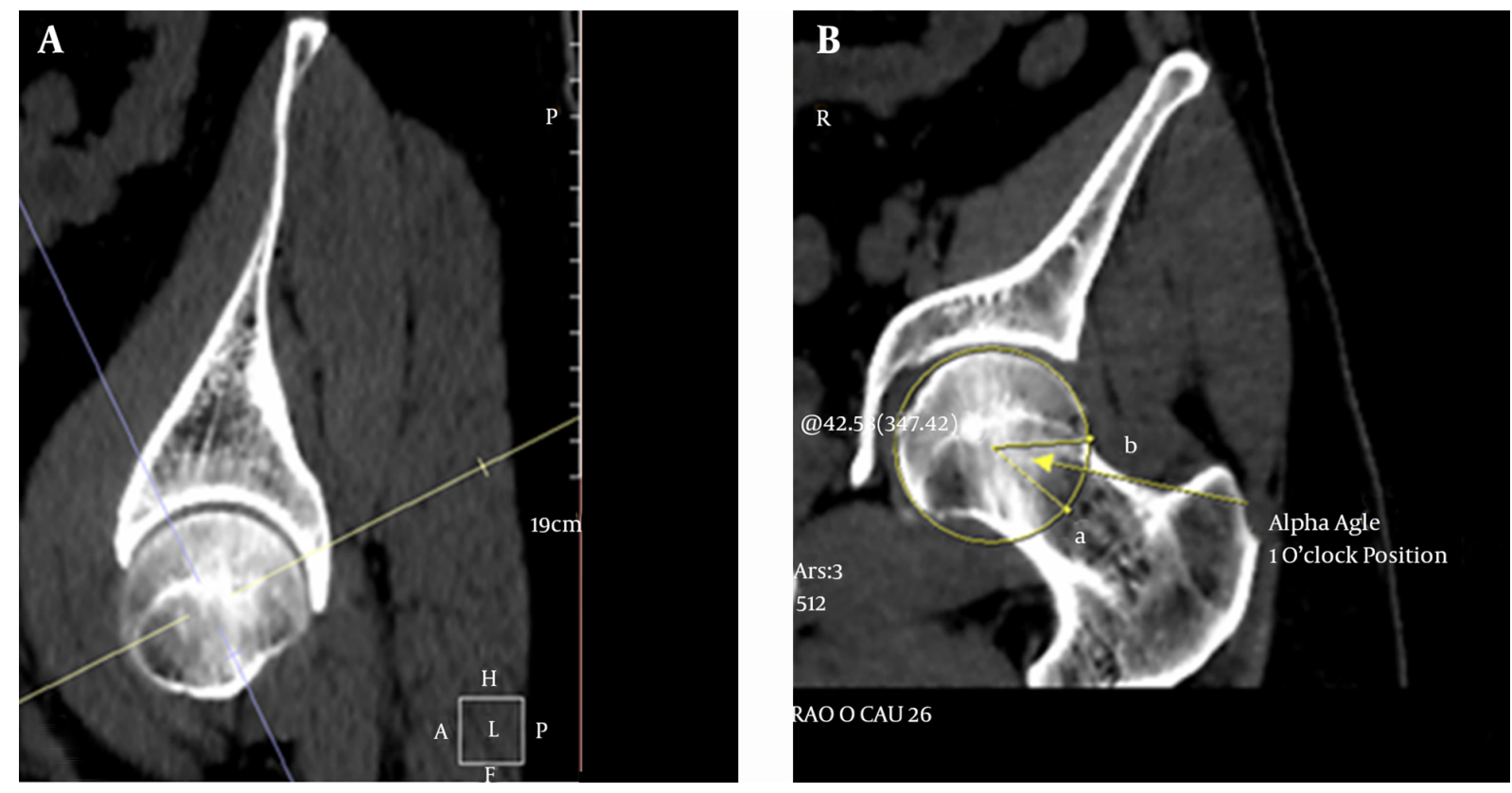

Figure 5. Alpha angle measurement in the one o'clock position. A, Reference plane for measuring the alpha angle in the one o'clock position; B, The angle was measured between line a, crossing the central axis of the femoral neck, and line b, joining the center of the femoral head, and the point where the radius of the femoral head exceeds the circle.

gists with regard to the AA measurements $(\mathrm{P}>0.05)$, which is shown in Figures 7 and 8.

The FHNO ranged from 5.41 to $14.41 \mathrm{~mm}$ (mean: $9.8 \mathrm{~mm}$, SD: $1.35 \mathrm{~mm}$, median: $9.7 \mathrm{~mm}$ ). Forty of 400 joints (10\%) had less than $8 \mathrm{~mm}$ anterior FHNO distances. The mean values for the FHNOs were $10.2 \pm 1.3 \mathrm{~mm}$ for the males and $9.5 \pm$ $1.1 \mathrm{~mm}$ for the females. Overall, there was a statistically sig- nificant gender difference for the FHNO $(\mathrm{P}<0.001)$.

With regard to the pincer-type FAI morphology, there were 223 pincer type morphological abnormalities in the sample population. In the male patients, 74 of 218 joints (33.9\%) had at least one, and 18 of 218 joints (8.3\%) had two or more morphological abnormalities associated with pincer FAIs. However, in the female patients, 101 of 182 joints 

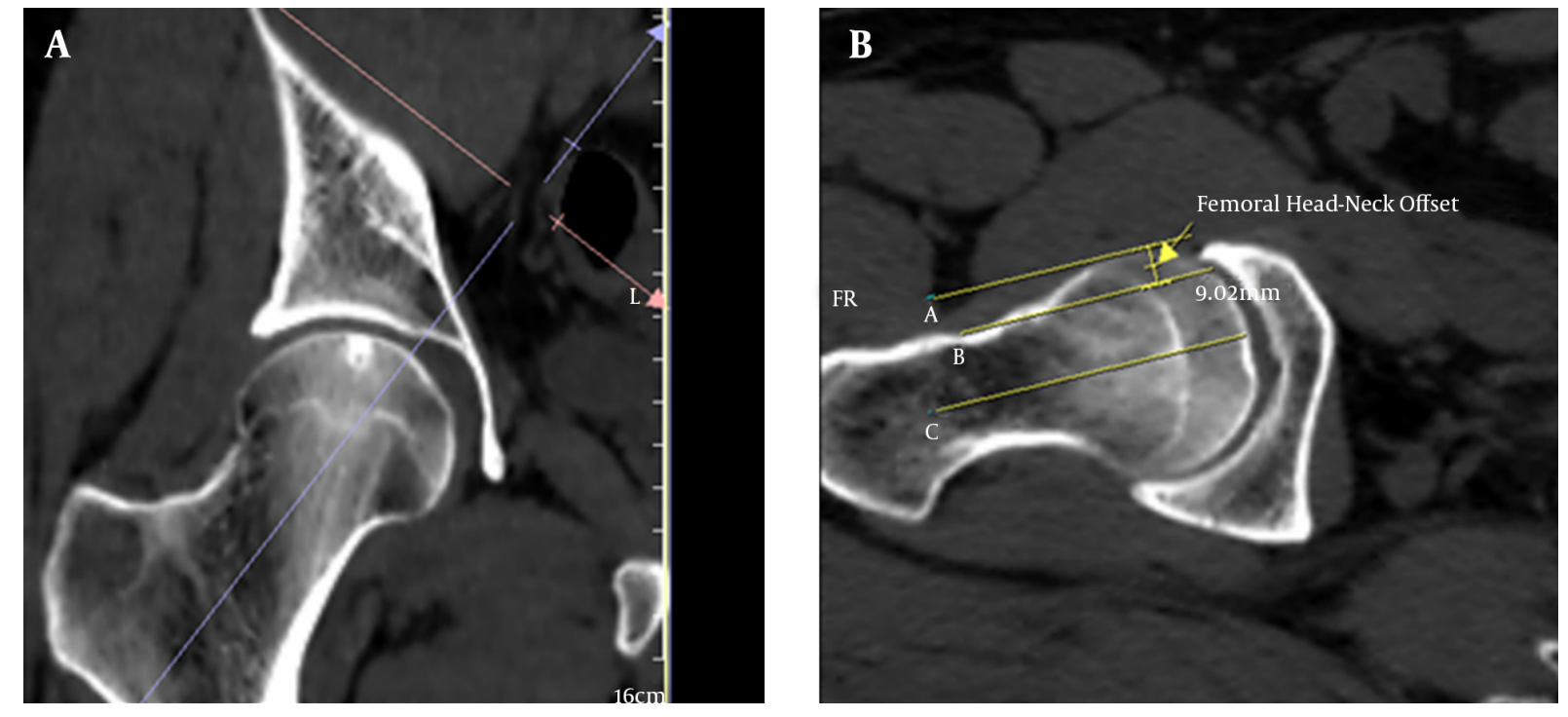

Figure 6. Femoral head-neck offset. A, Reference plane for measuring the femoral head-neck offset; $B$, The distance between lines a and $b$ was measured as the femoral headneck offset in the oblique axial plane. Line A is parallel to the anterior cortex of the femoral head, while Line B is parallel to the anterior aspect of the femoral neck cortex.

Table 1. Distribution of Cam Abnormalities According to Side and Sex

\begin{tabular}{|c|c|c|c|}
\hline \multirow{2}{*}{ Gender } & \multicolumn{2}{|c|}{ Alpha Angle $>55^{\circ}$} & \multirow{2}{*}{ Femoral Head-Neck Offset $<\mathbf{8}, \mathbf{m m}$} \\
\hline & Oblique Axial Plane & $\begin{array}{l}\text { Oblique Coronal Plane (1 O'clock } \\
\text { Position) }\end{array}$ & \\
\hline \multicolumn{4}{|l|}{ Men } \\
\hline Right & 19 & 25 & 8 \\
\hline Left & 28 & 35 & 20 \\
\hline Total & 47 & 60 & 28 \\
\hline \multicolumn{4}{|l|}{ Women } \\
\hline Right & 16 & 28 & 5 \\
\hline Left & 21 & 31 & 7 \\
\hline Total & 37 & 59 & 12 \\
\hline
\end{tabular}

(55.5\%) had at least one, and 27 of 182 joints (14.8\%) had two or more morphological abnormalities associated with pincer FAIs. Table 2 shows the number and distribution of the pincer type abnormalities according to the side and sex.

The AI ranged from $-10.4^{\circ}$ to $19.3^{\circ}$ (mean: $5.3^{\circ}$, median: $\left.5.2^{\circ}\right)$, and 41 of 400 joints $(10.3 \%)$ had a negative $\mathrm{AI}\left(<0^{\circ}\right)$. The mean values of the AIs were $5.0 \pm 4.9 \mathrm{~mm}$ for the males and $6.4 \pm 4.2 \mathrm{~mm}$ for the females, and there was a statistically significant gender difference with regard to the AI (P $=0.03$ ). The $\mathrm{AV}$ angle ranged from $-2.55^{\circ}$ to $34.25^{\circ}$ (mean: $18.6^{\circ}$, median: $19^{\circ}$ ), and 99 of 400 joints (24.75\%) had AV angles of less than $15^{\circ}$ (acetabular retroversion). The mean values of the AVs were $17.4 \pm 5.8 \mathrm{~mm}$ for the males and 19.6 $\pm 5.4 \mathrm{~mm}$ for the females, showing a statistically signifi- cant gender difference $(P=0.006)$.

The LCEA ranged from $19.3^{\circ}$ to $57.1^{\circ}$ (mean: $36.1^{\circ}$, median: $36.2^{\circ}$ ), and 83 of 400 joints $(20.75 \%$ ) had acetabular over-coverage (LCEAs greater than $40^{\circ}$ ). The mean values of the LCEAs were $37.5 \pm 5.8 \mathrm{~mm}$ for the males and $34.7 \pm$ $5.2 \mathrm{~mm}$ for the females, and there was a statistically significant gender difference for the LCEA $(\mathrm{P}<0.001)$. The Pearson's test showed a strong direct correlation between the AA values of the oblique axial plane and the radial plane (one o'clock position) $(\mathrm{r}=0.993, \mathrm{P}<0.001)$. In addition, there was a negative correlation between the AI and LCEA $(\mathrm{r}=-0.595, \mathrm{P}<0.001)$; however, there were no correlations detected between the other measurements. 
Table 2. Distribution of Pincer Type Abnormalities According to Side and Sex

\begin{tabular}{|c|c|c|c|}
\hline Gender & Acetabular Version Angle $>150$ & Lateral Center Edge Angle $>\mathbf{4 0 0}$ & Negative Acetabular Index \\
\hline \multicolumn{4}{|l|}{ Men } \\
\hline Right & 27 & 21 & 6 \\
\hline Left & 19 & 18 & 9 \\
\hline Total & 46 & 39 & 15 \\
\hline \multicolumn{4}{|l|}{ Women } \\
\hline Right & 25 & 29 & 14 \\
\hline Left & 28 & 15 & 12 \\
\hline Total & 53 & 44 & 26 \\
\hline
\end{tabular}

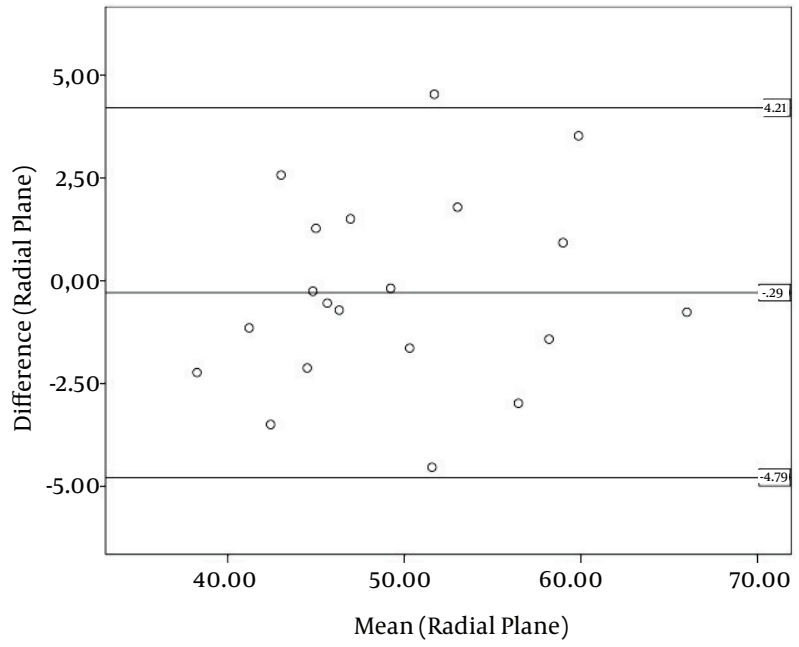

Figure 7. Bland-Altman plot representing a Scatter diagram of the differences between the two radiologists' radial plane (1 O'clock position) alpha angle measurements in relation to their mean values.

\section{Discussion}

This retrospective study showed that, in an asymptomatic young population, the frequency of radiological parameters associated with FAI is high. We found that $64.5 \%$ of the 400 joints had at least one, and $34.25 \%$ of the joints had two or more abnormal morphological parameters associated with FAIs. A review of the literature revealed that there are two types of studies describing the prevalence of the radiological parameters associated with FAIs in symptomatic and in asymptomatic patients. It has been shown in many studies that the prevalence of the radiological parameters is high in symptomatic patients. For example, Nogier et al. (10) found dysplasia, acetabular pincer effects, or cam effects in 95\% of 584 hips in symptomatic patients; and Ochoa et al. (11) found at least one abnormal

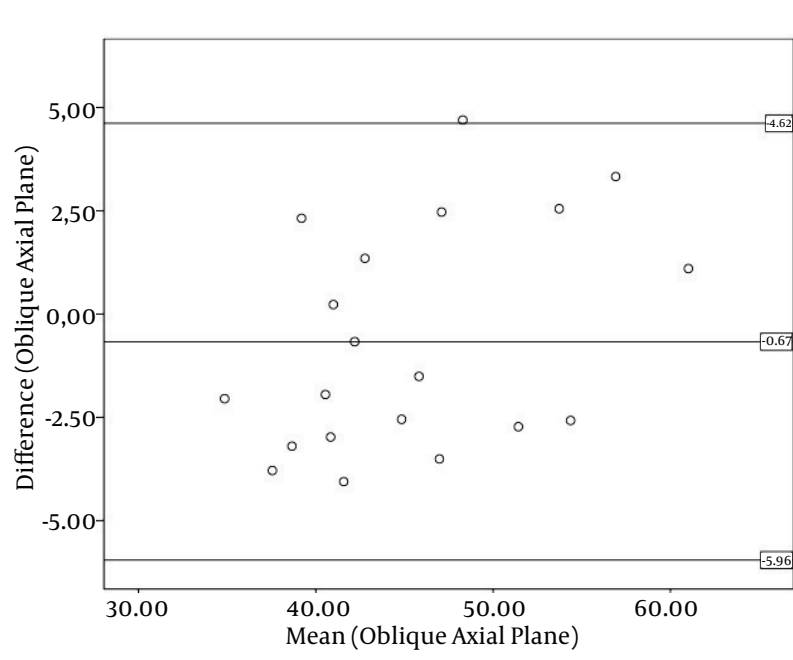

Figure 8. Bland-Altman plot representing a Scatter diagram of the differences between the two radiologists' oblique axial plane alpha angle measurements in relation to their mean values

parameter associated with FAIs in 135 of 155 patients (87\%) with symptoms. In addition, Bowler et al. showed that $65 \%$ of 142 patients who had undergone hip arthroplasty had abnormal AAs, indicating cam impingement (12).

In asymptomatic populations, most studies have focused on cam type morphological features, especially on the measurement of the AA. In only a few studies have both the cam and pincer type radiological parameters been analyzed in asymptomatic patients. For instance, Chakraverty et al. (2) found at least one abnormal parameter in $66 \%$ of 100 joints, and two or more abnormal parameters were present in $29 \%$ of the joints without symptoms. In another study, Kang et al. (13) found that $39 \%$ of 100 joints had at least one parameter, and that $11 \%$ had more than one parameter associated with FAIs in asymptomatic patients. Both studies used CT images in the assessment of the radi- 
ological parameters of the hips.

In this study, we evaluated six quantitative parameters (three cam and three pincer) associated with FAI morphology, and used reformatted CT images to calculate the AAs of the femoral head-neck junction in the anterosuperior quadrant, according to the studies of Chakraverty et al. (2) and Kang et al. (13). We performed quantitative analyses in only 200 patients (400 joints) and, to our knowledge, this study is the most comprehensive evaluation of FAIs in an asymptomatic population. Seventy-seven of 218 hips (35.3\%) in the men displayed at least one abnormality associated with cam FAI, while two or more abnormalities were seen in 48 of the 218 hips (22\%). Sixty-six of 182 women (36.3 \%) had at least one cam abnormality, and 39 of 182 (21.4\%) had two or more. No statistically significant gender difference was detected for the cam FAI morphology, but the overall prevalence was higher than previously reported. Reichenbach et al. (14) found that 67 of 244 (27.5\%) male patients without symptoms had cam type deformities on the hip MRIs. Furthermore, Hack et al. showed that $14 \%$ of 200 asymptomatic volunteers had at least one cam type abnormality in an MRI study (15).

Previous studies $(9,16,17)$ have shown that the measurement of the AA in reformatted radial images is more accurate than the measurement of the angle in the conventional axial oblique plane alone. Therefore, we used reformatted CT images to measure the AA along the anterosuperior quadrant of the femoral head-neck junction in two planes (oblique axial and radial one o'clock position). In addition, we defined an AA greater than $55^{\circ}$ to be abnormal in any plane, in accordance with previous studies (9, $16,17)$. We found that measuring the AA in the one o'clock position revealed more abnormalities than in the oblique axial plane, which was a statistically significant finding $(\mathrm{P}<$ 0.001 ). In our study, 79 of 218 hips (36.2\%) in the men and 96 of 182 hips (52.7\%) in the women had at least one pincer type characteristic. Moreover, twenty-seven hips in the women and 18 hips in the men had two or more characteristics associated with pincer FAIs. Overall, there was a statistically significant gender difference $(\mathrm{P}<0.001)$, and a female predominance in the prevalence of pincer type morphological features, in accordance with the literature $(2,13)$.

We found that only 60 of 400 joints (15\%) had mixed FAIs in our study. In the literature, an FAI has often been thought to represent mixed type features, but our findings showed little overlap, unlike those of previous studies $(4,18)$, and support the results of Cobb et al. (19) and Laborie et al. (20). In these studies, the authors concluded that the hips with cam and pincer deformities were distinct pathoanatomical entities; however, the low percentage of mixed FAI features could be due to the number of patients with pincer FAI features in this study. The radiologi- cal definitions of the thresholds used for pincer FAIs most often used standard pelvic radiographs, while CTs were less commonly used for this purpose. Therefore, these thresholds may have been larger if standard pelvic radiographs had been used. This study had several limitations. First, we worked on a population without histories or symptoms of hip-related problems with regard to our radiology and hospital databases. Second, we did not perform radial AA measurements through the entire circumference of the femoral head and neck. However, the large number of patients and the use of only quantitative measurements strengthened our study.

In this study, we found that the frequency of the cam and pincer FAI morphologies was high, even in an asymptomatic population, which was similar to the results of other studies. We speculate that the high frequency of abnormal morphologies associated with the FAIs of this healthy young population suggest that the threshold values may have been set too low in the current literature. In addition, the high prevalence of these findings may reflect anatomical variations, rather than true pathological abnormalities. Consensus is required on the threshold values with regard to what is normal and abnormal in all of the imaging modalities. For example, the threshold value of the AA has been suggested to be $50^{\circ}$ based on the MRI (21), and $55^{\circ}$ based on the CT (22). However, the reliability of its measurement and reproducibility have been questioned (23). We believe that the use of the $55^{\circ}$ threshold at the femoral head-neck junction on $\mathrm{CT}$ imaging may lead to overestimates of the contour abnormality. Additionally, we do not know how many or which parameters need to be present for the future development of symptomatic FAIs. Therefore, we could not determine what proportion of this population will have symptomatic FAIs in the future, when considering the radiological parameters alone. It is important to understand that the FAI is a morphological and dynamic syndrome. Other variables, such as the BMI (24), daily activity level, heavy work, and previous trauma, may be important in the development of symptoms. A study (7) have shown that the rate of hip implantation in ballet dancers at the age of 50 is $25 \%$. Moreover, in a sibling study, Pollard et al. showed that a sibling of a patient with a cam deformity has a relative risk of 2.8 , while the siblings of those patients with pincer deformities have a relative risk of 2.0 of having the same deformity, when compared with a control group (25). In this study, we found that the frequency of radiological parameters associated with cam and pincer FAIs is high, even in asymptomatic populations, as in other studies. This high frequency of abnormal radiological parameters associated with FAIs could be due to the low cutoff values in the current literature. Consensus is needed on the threshold values and the standard- 
ized imaging protocols of the hip for all imaging modalities. Those patients presenting with hip pain and indices of femoroacetabular impingement may be suitable candidates for early operative intervention to decompress the impingement, which may potentially delay or even prevent the progression of arthrosis.

\section{Footnotes}

Authors' Contribution: Study concept and design: Memik Teke, Celil Alemdar, and Cemil Goya; acquisition of data: Memik Teke and Cemil Goya; analysis and interpretation of data: Memik Teke and Cihad Hamidi; drafting of the manuscript: Mehmet Guli Cetincakmak, Salih Hattapoglu, and Emin Ozkul; study supervision: Aslan Bilici.

Financial Disclosure: The authors state that there are no financial interests related to the material in this manuscript.

Funding/Support: The authors state that there was no funding or support received for this study.

\section{References}

1. Tannast M, Siebenrock KA, Anderson SE. Femoroacetabular impingement: radiographic diagnosis-what the radiologist should know. AJR Am J Roentgenol. 2007;188(6):1540-52. doi: 10.2214/AJR.06.0921. [PubMed: 17515374].

2. Chakraverty JK, Sullivan C, Gan C, Narayanaswamy S, Kamath S. Cam and pincer femoroacetabular impingement: CT findings of features resembling femoroacetabular impingement in a young population without symptoms. AJR Am J Roentgenol. 2013;200(2):389-95. doi: 10.2214/AJR.12.8546. [PubMed: 23345362].

3. Leunig M, Ganz R. [Femoroacetabular impingement. A common cause of hip complaints leading to arthrosis]. Unfallchirurg. 2005;108(1):9-10. doi: 10.1007/s00113-004-0902-z. [PubMed: 15619064].

4. Beck M, Kalhor M, Leunig M, Ganz R. Hip morphology influences the pattern of damage to the acetabular cartilage: femoroacetabular impingement as a cause of early osteoarthritis of the hip.JBone Joint Surg Br. 2005;87(7):1012-8. doi: 10.1302/0301-620X.87B7.15203. [PubMed: 15972923].

5. Leunig M, Werlen S, Ungersböck A, Ito K, Ganz R. Evaluation of the Acetabular Labrum by Mr Arthrography.. J Bone Joint Surg Br. 1997;79B(2):230-4.

6. Clohisy JC, St John LC, Schutz AL. Surgical treatment of femoroacetabular impingement: a systematic review of the literature. Clin Orthop Relat Res. 2010;468(2):555-64. doi: 10.1007/s11999-009-1138-6. [PubMed: 19830504].

7. Ito K, Minka M2, Leunig M, Werlen S, Ganz R. Femoroacetabular impingement and the cam-effect. A MRI-based quantitative anatomical study of the femoral head-neck offset. J Bone Joint Surg Br. 2001;83(2):171-6. [PubMed: 11284559].

8. Wenger DE, Kendell KR, Miner MR, Trousdale RT. Acetabular labral tears rarely occur in the absence of bony abnormalities. Clin Orthop Relat Res. 2004(426):145-50. [PubMed:15346066].

9. Rakhra KS, Sheikh AM, Allen D, Beaule PE. Comparison of MRI alpha angle measurement planes in femoroacetabular impingement. Clin Orthop Relat Res. 2009;467(3):660-5. doi: 10.1007/s11999-008-0627-3. [PubMed: 19037709].
10. Nogier A, Bonin N, May O, Gedouin JE, Bellaiche L, Boyer T, et al. Descriptive epidemiology of mechanical hip pathology in adults under 50 years of age. Prospective series of 292 cases: Clinical and radiological aspects and physiopathological review. Orthop Traumatol Surg Res. 2010;96(8 Suppl):S53-8. doi:10.1016/j.otsr.2010.09.005. [PubMed 21035417].

11. Ochoa LM, Dawson L, Patzkowski JC, Hsu JR. Radiographic prevalence of femoroacetabular impingement in a young population with hip complaints is high. Clin Orthop Relat Res. 2010;468(10):2710-4. doi 10.1007/s11999-010-1233-8. [PubMed: 20107939].

12. Bowler, Declan J M, Fred Flandry. Prevalence of Femoroacetabular Impingement in Younger Patients Undergoing Total Hip Arthroplasty. $J$ Surg Orthop Adv.. 2012;21(3):122-25.

13. Kang AC, Gooding AJ, Coates MH, Goh TD, Armour P, Rietveld J. Com puted tomography assessment of hip joints in asymptomatic individuals in relation to femoroacetabular impingement. Am J Sports Med. 2010;38(6):1160-5. doi: 10.1177/0363546509358320. [PubMed 20228244]

14. Reichenbach S, Juni P, Werlen S, Nuesch E, Pfirrmann CW, Trelle S, et al Prevalence of cam-type deformity on hip magnetic resonance imag ing in young males: a cross-sectional study. Arthritis Care Res (Hoboken). 2010;62(9):1319-27. doi: 10.1002/acr.20198. [PubMed: 20853471].

15. Hack K, Di Primio G, Rakhra K, Beaule PE. Prevalence of camtype femoroacetabular impingement morphology in asymptomatic volunteers. J Bone Joint Surg Am. 2010;92(14):2436-44. doi: 10.2106/JBJS.J.01280. [PubMed: 20962194].

16. Kassarjian A, Brisson M, Palmer WE. Femoroacetabular impingement. Eur J Radiol. 2007;63(1):29-35. doi: 10.1016/j.ejrad.2007.03.020. [PubMed: 17485190].

17. Domayer SE, Ziebarth K, Chan J, Bixby S, Mamisch TC, Kim YJ. Femoroacetabular cam-type impingement: diagnostic sensitivity and specificity of radiographic views compared to radial MRI. Eur J Radiol. 2011;80(3):805-10. doi: 10.1016/j.ejrad.2010.10.016. [PubMed: 21074343].

18. Ganz R, Leunig M, Leunig-Ganz K, Harris WH. The etiology of osteoarthritis of the hip: an integrated mechanical concept. Clin Orthop Relat Res. 2008;466(2):264-72. doi: 10.1007/s11999-007-0060-z. [PubMed: 18196405]

19. Cobb J, Logishetty K, Davda K, Iranpour F. Cams and pincer impingement are distinct, not mixed: the acetabular pathomorphology of femoroacetabular impingement. Clin Orthop Relat Res. 2010;468(8):2143-51. doi: 10.1007/s11999-010-1347-z. [PubMed: 20431974].

20. Laborie LB, Lehmann TG, Engesaeter IO, Eastwood DM, Engesaeter LB, Rosendahl K. Prevalence of radiographic findings thought to be associated with femoroacetabular impingement in a population-based cohort of 2081 healthy young adults. Radiology. 2011;260(2):494-502. doi: 10.1148/radiol.11102354. [PubMed: 21613440].

21. Nötzli HP, Wyss TF, Stoecklin CH, Schmid MR, Treiber K, Hodler J. The contour of the femoral head-neck junction as a predictor for the risk of anterior impingement. J Bone Joint Surg Br. 2002;84-B(4):556-60.

22. Beaule PE, Zaragoza E, Motamedi K, Copelan N, Dorey FJ. Threedimensional computed tomography of the hip in the assessment of femoroacetabular impingement. J Orthop Res. 2005;23(6):1286-92. doi: 10.1016/j.orthres.2005.03.011.1100230608. [PubMed: 15921872].

23. Lohan DG, Seeger LL, Motamedi K, Hame S, Sayre J. Cam-type femoral-acetabular impingement: is the alpha angle the best MR arthrography has to offer?. Skeletal Radiol. 2009;38(9):855-62. doi: 10.1007/s00256-009-0745-3. [PubMed: 19565238].

24. Kumar R, Aggarwal A. Femoroacetabular impingement and risk factors: a study of 50 cases. Orthop Surg. 2011;3(4):236-41. doi: 10.1111/j.17577861.2011.00157.x. [PubMed: 22021139].

25. Pollard TC, Villar RN, Norton MR, Fern ED, Williams MR, Murray DW, et al. Genetic influences in the aetiology of femoroacetabular impingement: a sibling study.J Bone Joint Surg Br. 2010;92(2):209-16. doi 10.1302/0301-620X.92B2.22850. [PubMed: 20130310]. 